ТИПОЛОГИЯ НЕГАТИВНОСТИ В ИСТОРИИ АНТИЧНОЙ ФИЛОСОФИИ: К АНАЛИЗУ КОНЦЕПЦИЙ ДЕМОКРИТА, ПЛОТИНА И ДАМАСКИЯ

\author{
А. В. Богомолов ${ }^{1} *$ \\ ${ }^{1}$ Нижегородский государственный педагогический университет имени Козьмы Минина \\ (Мининский университет), Нижний Новгород, Российская Федераџия \\ *e-mail: ensestens@mininuniver.ru
}

\begin{abstract}
АННОТАЦИЯ
Введение: статья обращена к проблематике формирования апофатической традиции в истории античной философии. Акцент в исследовании делается на вопросе истока негативности в неоплатонизме, анализируются учения Плотина и Дамаския. Выдвигается гипотеза о том, что одним из оснований может являться учение Демокрита о двух видах пустоты.
\end{abstract}

Материалы и методы: в качестве материалов, используемых в статье, следует отметить переводы с древнегреческого языка свидетельств, передающих учение атомистов, а также обращение к аутентичным семантическим единицам. Сочинения Плотина и Дамаския анализируются на основании переводной литературы. Используются традиционные для историко-философского исследования методы: герменевтический, феноменологический, исторический, компаративный анализ.

Результаты исследования: исходной предпосылкой исследования являются свидетельства об учении атомистов, в которых есть указания на существование не одного, а двух видов пустоты. Подчеркивается, с одной стороны, именно гипотетический характер данного положения. С другой, говорится о вариативности трактовок анализируемых свидетельств. В статье показывается, что принцип дуализма негативности наличествует в учениях Плотина и Дамаския. В философии Плотина негативность представлена в двух противоположных полюсах иерархии - в генологии и в учении о материи. Показывается также, что в сложных апофатических конструкциях Дамаския говорится, в частности, о двух видах Единого.

Обсуждение и заключения: в завершении подчеркивается, что найти прямые указания в текстах Плотина и Дамаския на взаимосвязь их концепций с учением Демокрита о двух видах пустоты представляется затруднительным, и что наличествующие в статье выводы справедливы только в контексте общей логики формирования античной апофатики.

Ключевые слова: история философии, учение о пустоте, неоплатонизм, Единое, Дамаский, небытие, негативная теология.

Для цитирования: Богомолов А.В. Типология негативности в истории античной философии: к анализу концепций Демокрита, Плотина и Дамаския // Вестник Мининского университета. 2019. Т. 7, №2. С .12. 
TYPOLOGY OF NEGATIVITY IN THE HISTORY OF ANCIENT PHILOSOPHY: THE ANALYSIS OF THE CONCEPTS OF DEMOCRITUS, PLOTINUS AND DAMASCUS

\author{
A. V. Bogomolov ${ }^{1} *$ \\ ${ }^{1}$ Minin Nizhny Novgorod State Pedagogical University (Minin University), Nizhny Novgorod, \\ Russian Federation \\ *e-mail: ensestens@mininuniver.ru
}

\begin{abstract}
Introduction: the article is devoted to the problem of apophatic tradition formation in the history of ancient philosophy. The research focuses on the issue of the source of negativity in Neoplatonism, analyzes the teachings of Plotinus and Damascus. It is hypothesized that one of the grounds may be the doctrine of Democritus about two types of emptiness.
\end{abstract}

Materials and Methods: as the materials used in the article, it should be noted the translations from the ancient Greek language of the evidence, transmitting the teachings of the atomists, as well as the appeal to the authentic semantic units. The compositions of Plotinus and Damascus are analyzed on the basis of translated literature. Traditional methods of historical and philosophical research are used: hermeneutic, phenomenological, historical, comparative analysis.

Results: the initial premise of the study is evidence of the teachings of the atomists, in which there are indications of the existence of not only one, but two kinds of emptiness. On the one hand, it is the hypothetical nature of this provision that is emphasized. On the other hand, it is said about the variability of interpretations of the analyzed evidence. The article shows that the principle of dualism of negativity is present in the teachings of Plotinus and Damascus. In the philosophy of Plotinus, the negativity is presented in the two opposite poles of the hierarchy in henology and in teaching on the matter. It is also shown that in complex apophatic constructions of Damascus it is said about two types of the One.

Discussions and conclusions: in conclusion, it is emphasized that it is difficult to find direct instructions in the texts of Plotinus and Damascus on the relationship of their concepts with the teaching of Democritus about the two types of emptiness, and that the conclusions available in the article are valid only in the context of the general logic of the formation of ancient apophaticism.

Keywords: a history of philosophy, the doctrine of emptiness, Neoplatonism, One, Damascus, nonbeing, negative theology.

For citation: Bogomolov A.V. Typology of negativity in the history of ancient philosophy: the analysis of the concepts of Democritus, Plotinus and Damascus // Vestnik of Minin University. 2019. Vol. 7, no. 2. P.12.

\title{
Введение
}

Обращение к тематике негативности - одна из тенденций в современных исследованиях по истории философии. Ввиду того, что исток проблемы - античная философия, константное значение имеет актуальность историко-философских 
реконструкций представлений о небытии в греческой мысли. Однако, несмотря на наличествующий интерес, определенные аспекты не только предполагают проведение дополнительных исследований, но и нуждаются в проблематизации. Это, в частности, касается вопроса о демаркации видов негативности и необходимости дескрипции их различий. Вместе с тем даже само обращение к небытию сопряжено с традиционными трудностями, которые были сформулированы еще Парменидом и от которых, в значительной степени, несвободно наше мышление и сегодня [6]. Настоящее же исследование обращено к проблеме экспликации видов негативности, что обусловливает необходимость некоторых предварительных разъяснений.

Прежде всего заметим, проблема классификации негативности в греческой философии, безусловно, поднималась в научной литературе - как в отечественной, так и зарубежной. Без преувеличения особое место здесь занимает небольшая, но важная работа «Apophatisme et théologie negative» [26]. Ee aвтор, P. Hadot, обращает внимание на необходимость различия трех терминов: «апофазис», «аферезис» и «негативная теология». В специальных исследованиях данная работа становилась предметом анализа [13; 5], поэтому мы не будем подробно останавливаться на конкретизации смыслов этих понятий. Отметим лишь, что, по мнению П. Адо, «аphairesis» представляет собою «отделение того, что не сущностно важно: мысль наделена способностью производить такое отделение» [1 с. 216]. «Apophasis» характеризуется как «общий смысл демарша ума, нацеленного на трансцендентность путем негативных предложений» [1, с. 215]. Значение же термина «негативная теология» ввиду целого ряда особенностей, обозначаемых автором, подвергается пересмотру. Так, говорится: «негативная теология будет отрицать от своего объекта само божество, поскольку речь еще бы шла о воспринимаемом определении. Слово «теология» (то есть «речь о Боге») больше не оправдало бы себя», ввиду чего надлежало бы «говорить скорее об апофатизме...или об аферетическом методе.., чем о негативной теологии» [1, с. 215]. Кроме того, и термин «негативная теология» может пониматься в нескольких смыслах, что также отмечено в исследованиях, давно ставших классическими [10, с. 363].

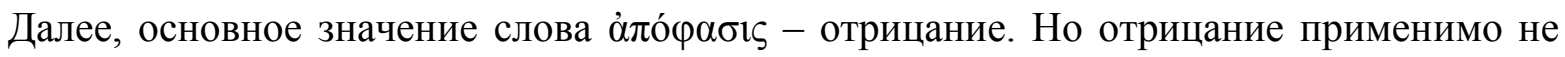
только в теологическом контексте. И здесь поднимаемая в настоящей статье проблема приобретает иной контекст - речь о различии философской апофатики и апофатической теологии. В самом деле, можно согласиться с тем, что часто «а-теологическая сущность апофазиса остается незамеченной» [8, с. 11], ввиду чего имплицитно наличествует заблуждение о том, что апофатическим может быть только богословие. Разумеется, это не так и, более того, имеет смысл предположить, что именно философская апофатика является теоретическим основанием негативной теологии, исторически предшествует ей [13].

Мы обозначили лишь некоторые аспекты проблемы демаркации видов негативности. Подробнее, насколько это возможно, учитывая формат статьи, данный аспект в изучении греческого апофазиса можно рассмотреть лишь в оптике отдельных школ или персоналий. В рамках настоящего исследования мы обратимся к учениям Демокрита, Плотина и Дамаския Диадоха. Разумеется, такой выбор персоналий отнюдь неочевиден и также нуждается в обосновании. В общей логике развития греческой негативности и учение атомистов, и концепции неоплатоников имеют важное значение. Атомисты первыми в западной традиции выдвинули тезис о существовании несуществующего, понимаемого как пустота. Само по себе это обстоятельство весьма примечательно. Но интересным также видится вопрос о возможном наличии двух видов пустоты в учении Демокрита [11, с. 267]. В философии 


\section{History of philosophy}

неоплатонизма проблематика негативности одна из ключевых. Во-первых, учение о Едином можно представить как негативную теологию. Во-вторых, в контексте рассматриваемой проблемы важное значение имеют также и учения о материи в системах неоплатоников. Выбор представителей обусловлен очевидным, как представляется, обстоятельством. Плотин является основателем школы и, соответственно, именно он формулирует основные положения, в частности, негативной теологии, а Дамаский - неоплатоник, в воззрениях которого проблематика негативности, по вполне понятным причинам, получает свое завершение.

Сказанное, однако, не вносит окончательной ясности относительно принципа выбора персоналий, поэтому отметим следующее. В плотиноведении прочно укрепилась точка зрения, согласно которой истоком негативности в генологии Плотина является диалог «Парменид» [22]. В целом, это, конечно, так, но только этим диалогом проблема историкофилософских оснований учения о Едином не исчерпывается, и это обстоятельство также находит отображение в специальной литературе. Так вот поиск «неплатоновских» оснований негативного аспекта учения о Едином в неоплатонизме позволяет предполагать наличие взаимосвязей с учениями о негативности в предшествующих концепциях. Как мы полагаем, одним из таких оснований может быть учение о небытии в онтологии атомистов.

Таким образом, в рамках настоящей статьи мы обращаемся к проблеме историкофилософских оснований негативного аспекта теологии неоплатоников. Цель - рассмотрение гипотезы, согласно которой учение Демокрита о двух видах пустоты можно считать одним из истоков негативности в философии Плотина и Дамаския.

\section{Обзор литературы}

Исследования по истории античной философии, помимо прочего, часто сопряжены с двумя трудностями. С одной стороны, число источников, в которых в той или иной степени затрагивалась бы исследуемая проблема, едва ли поддается простому перечислению. С другой, конкретный аспект проблемы оказывается изученным в недостаточной степени. Не свободна от этих затруднений и настоящая статья. В своем обзоре мы обозначим некоторые источники, которые по определенным основаниям следует отнести к значимым для данного исследования и к которым можно обратиться при дальнейшем изучении темы. В числе таковых, к примеру, «Негативная теология» П. Адо. Далее, методология исследования апофатики представлена и в работах отечественных специалистов. Так, особо хотелось бы отметить диссертационное исследование В.Н. Дробышева «Апофатическая рациональность и ее трансформация в современной западной философии» [8], а также труды других авторов [5; 9; 13;]. К этой же группе исследований мы отнесем и работы, посвященные самым разным аспектам категории небытия, которые также важны для понимания специфики негативности [12; 17].

Другую группу представляют исследования, затрагивающие непосредственно историко-философский контекст. Вполне очевидно, что здесь мы можем обозначить лишь малую часть, но сделать это попытаемся, соблюдая баланс классических и современных исследований. Итак, сначала отметим исследования по философии Демокрита. Прежде всего, выделим известную книгу С.Я. Лурье [11], которая являет собою систематизацию свидетельств о философии мыслителя из Абдер. Далее, выделим несколько работ зарубежных авторов: «Левкипп, Демокрит и Кант: размышления об эквивалентности между бытием и небытием» [23], а также статью, посвященную проблеме именования двух начал - 
атомов и пустоты [32]. К современным исследованиям атомизма отнесем также публикацию «Elements in the atomism theory, according to Aristotle» [25].

В числе источников по неоплатонизму в группе классических работ выделим исследования А.Ф. Лосева [10], Э. Доддса [22], А. Армстронга [18], Д. Диллона и Л. Гершона [21; 24], Дж. Риста [15; 33]. В числе современных исследований можно отметить работы, затрагивающие разные аспекты генологии Плотина $[19 ; 20 ; 21 ; 28 ; 29]$. Здесь же отметим исследования, касающиеся вопросов влияния учения Плотина на последующую традицию [31; 34], а также работы, посвященные анализу учений, оказавших влияние на формирование уже самого неоплатонизма [35]. И, наконец, выделим несколько исследований современных авторов, в которых затрагивается учение Дамаския Диадоха [27; 30; 36].

\section{Материалы и методы}

В настоящей статье мы обращаемся к непростой проблеме, требующей уточнений по целому ряду параметров, в т.ч. методологии, прояснению терминов и пр. Во-первых, отметим, что проблематика негативности тесно связана с категорией небытия, небытие является «регулирующей идеей апофазиса» [8, с. 11]. И здесь возникает первая сложность. В неоплатонизме небытие - это, в конечном счете, низшая ступень иерархии, т.е. материя. Мы же используем этот термин иначе, а именно в том смысле, в котором данная категория употребляется в классической философии. Является ли материя таким небытием у неоплатоников - это вопрос, к которому мы обратимся ниже. Сейчас лишь отмечаем наличие данного противоречия. Далее, во-вторых, нельзя обойти вниманием «источниковедческий» аспект. В исследовании данного формата мы практически не обращаемся к греческим текстам, ибо в противном случае рискуем существенно выйти за рамки допустимого объема. Поэтому использоваться будет преимущественно переводная литература. В-третьих, надлежит подчеркнуть, что особое значение для формирования негативности в неоплатонизме занимает философия Платона. Однако, эта тема нами практически не затрагивается. Обусловлено это несколькими причинами. В частности, проблема влияния диалога «Парменид» на генологию Плотина в специальной литературе рассмотрена основательно. К тому же проблематика настоящей статьи предполагает экспликацию именно «неплатоновских» оснований, одним из которых, предположительно является учение атомистов о пустоте. Ввиду сказанного философия Платона остается как бы «за скобками» в нашем исследовании. В-четвертых, мы обращаемся к учению первых греческих атомистов, т.е. к философии Левкиппа-Демокрита. Здесь необходимо сделать в целом традиционные для анализа их философии замечания. Ввиду того, что учение Демокрита известно в большей степени, мы и используем имя философа из Абдер, а вопрос о различении воззрений двух философов не представляется для наших целей значимым. Случаи же употребления сочетания двух имен в последующем тексте продиктованы лишь некими стилистическими требованиями. И наконец, в-пятых, собственно, методологическая база включает в себя несколько традиционных для историко-философского исследования методов. Поскольку мы обращаемся к источникам, пусть и в их переводах, то необходимым оказывается герменевтический метод. В определенном отношении применяется феноменологический метод, метод историко-философской реконструкции, компаративный анализ. 


\section{Результаты исследования}

Важной задачей при обращении к учению древних атомистов о пустоте, как мы полагаем, является ограничение анализируемых сведений, передающих эту часть их воззрений. Сколь бы парадоксально ни выглядел данный тезис, именно в рамках настоящей статьи он имеет особую актуальность. Во-первых, необходимо учитывать, что тематика первоначал в атомизме исследована в достаточной мере. Указанное обстоятельство ни в коем случае не означает «снятия» этой проблемы для историков античной философии. Мы лишь обозначаем, что предметное поле должно являть собою акцент на определенном аспекте, дабы исследование не содержало системного перечисления хорошо известных свидетельств доксографии. Во-вторых, в рамках предшествующих обращений к данной тематике нами был осуществлен анализ учения Демокрита о пустоте, где мы также подробно рассматривали значительную часть таких свидетельств [2, с. 41-72; 3].

Итак, мы обращаемся к вопросу о наличии в учении Демокрита двух видов пустоты. С.Я. Лурье, классифицируя соответствующие фрагменты, говорит о промежуточной и

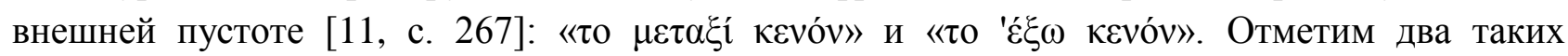
свидетельства. Одно из них принадлежит Филопону, другое - Симпликию. В первом случае мы находим следующее утверждение: «Вне же космоса есть пустота, существующая отдельно» [11, с. 267]. В свидетельстве Симпликия наличествует схожая по своей сути формулировка: «не только в космосе есть некая пустота, но и вне космоса; ясно, что эта пустота уже не только место, но существует сама по себе» [11, с. 267]. Далее, возникает вопрос об основаниях необходимости наличия двух видов пустоты. Таким основанием, вполне очевидно, является утверждение о существовании не одного, а многих миров в космологии Демокрита. В самом деле, в данном контексте демаркация двух видов пустоты становится вполне объяснимой: если внутренняя пустота разделяет тела и атомы, то внешняя - миры и атомы. И положение о наличии такой, внешней, пустоты представляется, по меньшей мере, непротиворечащим общей концепции Левкиппа-Демокрита.

Отметим, данный аспект учения первых атомистов становился предметом исследований, хотя и не столь часто. К примеру, В.П. Визгин отмечал: «если мы присмотримся к свидетельствам об атомистах, то увидим, что самостоятельным статусом существования наделяется у них «великая пустота» и она «разделяет миры точно так же, как внутрикосмическая пустота разделяет атомы» [4, с. 86]. Однако, трактовка различия видов пустоты может иметь и иное основание. В свидетельствах, передающих учение атомистов, нет единого слова, которым обозначалось бы «неатомистическое первоначало». Таких слов,

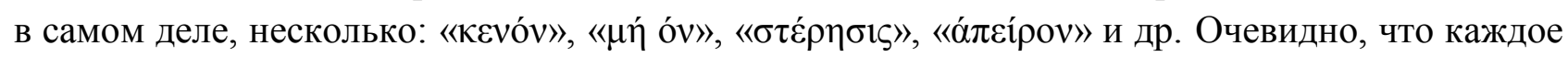
из них имеет свои смысловые оттенки. Полисемантичность «неатомистического первоначала», разумеется, не означает многих видов негативности в атомизме, а демонстрирует, пожалуй, трудность, с которой сталкивались доксографы при передаче соответствующего содержания. Поэтому здесь следует обратить внимание на то, что различия надлежит искать не столько в семантике, сколько в онтологии, космологии и гносеологии атомистов. В связи со сказанным, в предыдущих исследованиях мы обратили внимание на то, что различие между внутренней и внешней пустотой гипотетически можно интерпретировать как едва ли не первое в истории европейской мысли разделение ничто и небытия [2, 41-72]. Во фрагментах мы, разумеется, не найдем указаний на наличие именно такой трактовки различия. Кроме того, демаркация «небытия» и «ничто» - это проблема гораздо более позднего происхождения. Впрочем, совсем не исключено, что ее истоком 
является как раз греческая негативность. Но данная интерпретация двух видов пустоты в атомизме имеет именно гипотетический характер. Следует также отметить, какой бы трактовка ни была мы все же склонны полагать, что допущение существования именно двух видов пустоты в атомизме имеет определенные основания.

Следовательно, в атомизме Левкиппа-Демокрита наличествует не просто тезис о существовании негативного, понимаемого в качестве пустоты, но также и проблематизация соотношения видов негативности. Впрочем, в рамках настоящей статьи указанное обстоятельство интересно нам именно в контексте последующих трансформаций представлений о негативности. В частности, речь о концепциях неоплатоников.

Анализ негативности в неоплатонизме предполагает, прежде всего, обращение к иерархии. К примеру, в концепции Плотина негативность явлена в двух ее противоположных частях - в генологии и в учении о материи. Так, в последнем трактате VI книги «Эннеад» говорится о том, что Единое нельзя даже и называть Единым, ибо любой случай именования - ограничение. Оно не нуждается ни в чем, в том числе, и в самом себе. Кроме того, Единое недоступно познанию [18, с. 301-345]. Далее, Единое у неоплатоников - бог. В конечном счете, апофатический метод дескрипции бога и обусловливает дискуссии об онтогносеологическом статусе и является основанием для понимания Единого как ничто. Вместе с тем, надлежит ли считать, что Единое - это ничто? В специальной литературе есть разные точки зрения на этот счет. Мы склонны полагать, что Единое не следует интерпретировать исключительно де-онтологически. В самом деле, если основанием «ничтойности» являются апофатические характеристики, то не следует упускать из виду и наличие положительных суждений. В данном случае можно, конечно, возразить указанием на вынужденную необходимость катафатики, которая обусловлена ограниченностью мышления и языка. Но здесь важно, что Единое, помимо прочего, понимается и как Первоначало, а кроме того и как Сверхблаго. Поэтому Единое не есть ничто, но является сверхтрансцендентным нечто. Но, поскольку Оно таково, т.е. так как Единое сверхтрансцендентно, Оно граничит с ничто.

Не менее важным в контексте рассматриваемой проблемы является и учение о материи в философии Плотина. В этой части концепция основателя неоплатонизма, пожалуй, особо близка к воззрениям Платона. И во многом позиции философов здесь совпадают. В частности, это касается и вопроса об онтологическом статусе материи. Так, например, наличествует суждение: «материя бескачественна только в том смысле, что сама по себе она чужда всех тех качеств, которые может она усвоить себе как воспринимающая основа, а не в том смысле, что она не имеет никакой природы» [14, с. 43]. Данная трактовка по своей сути близка к тому, что говорится в «Тимее». И нас, главным образом, интересует, что и у Платона, и в философии Плотина материя по своему статусу близка к небытию, но таковым не является ввиду того, что она в каком-то отношении все же существует или, как мы видим, она имеет некую «природу». Однако концепция материи у Плотина содержит еще один важный аспект, а именно т.н. умную материю, т.е. материю, которая находится в Уме и является «вместилищем эйдосов». О различии двух видов материи можно говорить в нескольких отношениях, но вне всяких сомнений характерная особенность умной материи в том, что она сохраняет черты негативности. И значимым моментом является то, что материя существует во второй ступени иерархии, т.е. негативное приближено к Единому. Из этого положения следует, что негативность является системно значимым элементом в иерархии.

Таким образом, в философии Плотина о негативности можно говорить, по меньшей мере, в двух отношениях: и в генологии, и в учении о материи наличествует интенция к деонтологизации Единого и материи соответственно. Такое «совпадение» противоположных 


\section{History of philosophy}

полюсов само по себе явление, конечно, примечательное, и открывающее широкий простор для упражнений в диалектике с последующими вполне очевидными, впрочем, выводами.

Теперь обратимся к проблеме негативности в учении Дамаския Диадоха. Здесь, разумеется, надо оговориться, что Дамаский - последний крупный представитель неоплатонизма, и что с момента начала деятельности Плотина проходит время равное нескольким столетиям. Между Плотином и Дамаскием были значимые, яркие фигуры, без которых трудно представить неоплатонизм - это и Порфирий, и Прокл, и Ямвих. Но интересным представляется проанализировать именно начальную фазу становления негативности в философии Плотина и завершающую, т.е. к чему приходит диалектика апофазиса в неоплатонической традиции. Ключевым моментом здесь является генология.

В целом учение о Едином в философии Дамаския находится в рамках неоплатонической традиции. Единое немыслимо, невыразимо, непознаваемо. Обратимся к одному из фрагментов текста Дамаския: «единое в нас, определяемое как сопутствующее нам, родственное нам и почти во всем отстающее от того, вполне готово к подобному восприятию. Переход от того, в отношении чего сделаны некоторые предположения, к тому, что есть просто само по себе, легок; пусть даже мы никоим образом не обратились бы к последнему - все равно, опираясь на то простое, что есть в нас, мы способны высказать предположения о том, что предшествует всему. Именно в этом смысле единое изреченно и в этом же - неизреченно; а что касается высшего единого, то пусть оно будет почтено совершенным молчанием и прежде всего полным неведением, отвергающим всякое знание» [7, с. 14]. Здесь мы видим не только указание на трудности в описании, познании Единого, но и мысль о том, что, по Дамаскию, Единое не одно. Причем о некотором Едином можно говорить, о другом не надлежит высказываться. В специальных исследованиях на подобное различие, безусловно, обращается внимание. Так, Е.Н. Собольникова отмечает: «Если в первом аспекте Единое подразумевает многое, то есть множественность идей оказывается просто иной стороной Единого, которое является онтологическим условием существования умопостигаемого космоса и вообще бытия всякой вещи в ее самотождественности (единстве). Во втором аспекте - в качестве непричастного множественности Единое оказывается невыразимым в понятии, то есть, находится за пределами нашего познания, более того, оно находится за пределами бытия (трансцендентно ему), поскольку прибавление предиката бытия к Единому приведет к тому, что оно становится двойственным» [16]. Приведенный фрагмент и комментарий к нему демонстрирует, что в генологии Дамаския есть, по меньшей мере, два смысла, в которых можно говорить о Едином. И особо выделяется некое высшее Единое, которое абсолютно непознаваемо и невысказываемо.

Подчеркнем, что проблематика апофазиса в воззрениях Дамаския является одним из ключевых аспектов его учения, и мы лишь отчасти затронули значение негативности в контексте генологии. Однако и представленная часть чрезвычайно важна для рассматриваемой в настоящем исследовании проблемы. Подведем теперь некоторые итоги.

Одним из источников формирования греческой апофатической традиции можно считать учение атомистов о небытии, понимаемом как пустота. Причем о пустоте в нескольких свидетельствах доксографии говорится в двух значениях. Дуалистический принцип онтологии и эпистемологии негативности, как мы полагаем, получает дальнейшее развитие в учениях неоплатоников - Плотина и Дамаския. В философии Плотина негативность явлена в генологии и в учении о материи; в воззрениях Дамаския Диадоха наличествует также и двоякое понимание Единого. 


\section{Обсуждение и заключения}

Становление греческой апофатической традиции - сложный многофакторный процесс. Выявление закономерностей в нем является одной из задач, решение которой предполагает приращение знания для истории философии как науки. Безусловно, в рамках отдельно взятой статьи нельзя охватить значительной части учений, формирующих проблемное поле греческой негативности. Однако от выбора персоналий во многом зависит потенциальная новизна исследования.

Так, важным представляется вопрос об истоках апофатики в неоплатонизме. С одной стороны, эта тема чрезвычайно проста, ибо в нашем распоряжении предостаточное количество исследований, в которых говорится о том, что таковым истоком является философия Платона и в особенности диалог «Парменид». Попытки отрицания истинности данного положения представляются спорными. Во всяком случае, мы не склонны подвергать сомнению данной историко-философской взаимосвязи. Другое дело в том, что философия Платона - это не единственный такой источник. Если говорить именно о становлении проблематики негативности, то чрезвычайно важное значение имеет учение ЛевкиппаДемокрита о пустоте. Примечателен, конечно, и сам факт утверждения бытия небытия. Но еще более интересна ситуация с возможным наличием двух видов пустоты. Мы полагаем, что такой, своего рода, дуализм в понимании негативности имеет определенное значение в логике формирования апофазиса. Во всяком случае, в учении Плотина, как это было показано, также можно говорить о дуализме. В первом случае - это апофатика Единого, во втором - учение о материи. В контексте сказанного, разумеется, возникает вопрос о том, наличествует ли нечто подобное в философии Платона. Сравнение учения о пустоте в атомизме и философии Платона - один из важных и интересных моментов в изучении апофатической традиции и, возможно, станет предметом следующих исследований. Сейчас же эту тему неизбежно надлежит обойти.

Далее, выделим еще один момент, позволяющий говорить об определенном сходстве в учении атомистов и Плотина. Как мы отмечали выше, одна из особенностей свидетельств, передающих учение Демокрита, заключается в том, что отсутствует единое слово, отображающее именование «неатомистического первоначала». Это связано, как представляется, и с тем, что сложно подобрать понятие, которое отображало бы парадокс бытия небытия. В определенном отношении это напоминает те трудности, которые мы обнаруживаем в текстах «Эннеад» при описании Единого. В самом деле, даже необходимость использования катафатических суждений напоминает трудности доксографии при именовании того, что существует, будучи ничем, отсутствием. И здесь негативная теология, т.е. системное применение отрицательных суждений в отношении трансцендентного нечто, предстает как преодоление невысказываемости о существовании пустоты.

Сказанное о взаимосвязи дуалистического принципа негативности в онтологии и космологии атомистов и учением о негативности в философии Плотина во многом схоже и с апофатикой в учении Дамаския. Однако в воззрениях Дамаския Диадоха наличествует дихотомия самого трансцендентного начала - указывается на запредельную трансцендентность «высшего» Единого.

В завершении хотелось бы подчеркнуть, что в текстах Плотина и Дамаския мы с высокой долей вероятности не найдем прямых и непротиворечивых отсылок к анализируемым выше свидетельствам, передающих учение атомистов. В рамках настоящей 


\section{History of philosophy}

статьи мы реконструировали фрагмент чрезвычайно противоречивого процесса становления апофатической традиции в истории античной мысли. И об указанной взаимосвязи мы говорили именно в контексте этого общего процесса. И наконец, поскольку речь велась о типологии негативности, то следует отметить, что в концепции атомистов наличествует учение о двух типах пустоты, понимаемых как условие существования, в одном случае, самих атомов и тел, в другом - как условие существования многих миров. В философии Плотина негативность затрагивает и Первоначало, и низшую ступень в иерархии, т.е. материю. В воззрениях Дамаския Диадоха дихотомия касается уже самого трансцендентного - Единого.

\section{Список использованных источников}

1. Адо П. Негативная теология // Адо П. Духовные упражнения и античная философия. М.; СПб.: Изд-во «Степной ветер»; ИД «Коло», 2005. 448 с.

2. Богомолов А.В. Диалектическое решение проблемы небытия в истории древнегреческой философии (досократический и классический этап): дис. ... канд. филос. наук: 09.00.03. Н. Новгород, 2014. 161 с.

3. Богомолов А.В. Разделение категорий «ничто» и «небытие» в философии Демокрита. К обоснованию необходимости нонэссеологии // Credo new. 2012. №1. С. 12-25.

4. Визгин В. Я. Взаимосвязь онтологии и физики в атомизме Демокрита (на примере анализа понятия пустоты) // Философия природы в античности и в средние века. М., 2000. C. 78-90.

5. Вишняков В.П. Апофатический метод в «Пире»: между аферезой и апофазой // Платоновские исследования. 2016. №2. С. 164-186.

6. Воробьев Д.В. Роль ничто в реальности умственных построений: дис. ... д-ра филос. наук: 09.00.01. Н. Новгород, 2010. 359 с.

7. Дамаский Диадох. О первых началах: Апории, относящиеся к первым началам, и их разрешение: Комментарий к «Пармениду» Платона. СПб.: Изд-во Русского Христианского гуманитарного института, 2000. 1071 с.

8. Дробышев В.Н. Апофатическая рациональность и ее трансформация в современной западной философии: дис. ... д-ра филос. наук: 09.00.03. СПб., 2016. 338 с.

9. Каюмов А.Т., Красильников В.А. Сущностные характеристики различий в рассмотрении понятия «небытие» на примере учений древнеиндийской и древнегреческой философии // В мире научных открытий. 2015. №11(71). С. 377-387.

10. Лосев А.Ф. История античной эстетики. Поздний эллинизм. Харьков: Фолио; М.: ООО «Издательство АСТ», 2000. 960 с.

11. Лурье С.Я. Демокрит. Тексты. Перевод. Исследования. Л; М.: Наука, 1970. 666 с.

12. Ничто / под ред. Д. Уэбба; пер. с англ. А. Капанадзе. М.: Лаборатория знаний, 2016. 237 c.

13. Оплетаева О.Н. Истоки и смысл апофатической традиции. Философия и теология // Вестник адыгейского государственного университета. Серия 1: Регионоведение: философия, история, социология, юриспруденция, политология, культурология. 2010. №4. С. 30-36.

14. Плотин. Сочинения. Плотин в русских переводах. СПб.: «Алетейя» при участии Греколатинского кабинета Ю.А. Шичалина. М., 1995. 672 с.

15. Рист Дж. М. Плотин: путь к реальности / пер. с англ. Е.В. Афонасина, И.В. Берестова. СПб.: Издательство Олега Абышко, 2005. 320 с. 
16. Собольникова Е. Н. «Выводы о невозможном»: к проблеме интерпретации мистического опыта в философии Дамаския Диадоха. URL: http://www.plato.spbu.ru/CONFERENCES/2018/ther110.html (дата обращения: 20.04.2019).

17. Шпека К.А. К проблеме содержания понятия небытия // Философия и наука. 2016. Том 15. C. 337-344.

18. Armstrong A.H. Plotinus Vol. VII, Ennead VI.6-9. Loeb Classical Library, 1988. 345 p.

19. Calvo J.M.Z. El primer principio, 'potencia de todas las cosas', en Plotino // Éndoxa: Series Filosóficas. 2016. Issue 38. Pp. 131-144.

20. Cohoe C.M. Why the One Cannot Have Parts: Plotinus on Divine Simplicity, Ontological Independence, and Perfect Being Theology // Philosophical quarterly. 2017. Vol. 67(269). Pp. 751-771.

21. Dillon J., Gershon L. Neoplatonic philosophy: introductory readings. Indianapolis: Hackett Publishing Co, 2004. 373 p.

22. Dodds E.R. The Parmenides of Plato and the Origin of the Neoplatonic 'One' // The Classical Quarterly. 1928. Vol. 22, no. 3. Pp. 129-142.

23. Dos Santos E. E. Leucipo, Demócrito e Kant: uma Reflexão sobre a Equivalência entre Ser e Não-Ser // TRANS-FORM-ACAO. 2015. Vol. 38. Issue 2. Pp. 71-94.

24. Gerson L.P. The 'Neoplatonic' Interpretation of Plato's Parmenides // International journal of the platonic tradition. 2016. Vol. 10. Issue 1. Pp. 65-94.

25. Gomes G.L. Elements in the atomism theory, according to Aristotle // Hypnos. 2018. Issue 41. Pp. 146-165.

26. Hadot P. Apophatisme et théologie négative // Exercices spirituels et philosophie antique. Paris. Études augustiniennes, 1987. Pp. 185-193.

27. Hoffmann P. Les âges de l'Humanité et la critique du christianisme selon Damascius // La Revue de l'histoire des religions. Vol. 234. Issue. 4. Pp. 737-775.

28. Lavaud L. The Primary Substance in Plotinus' Metaphysics: A Little-Known Concept // Phronesis. 2014. Vol. 59. Pp. 369-384

29. Lee S. The Dynamic Association of Being and Non-Being: Heidegger's Thoughts on Plato's Sophist Beyond Platonism // Human studies. 2016. Vol. 39. Issue 3. Pp. 385-403.

30. Moraru C.-F. The Forbidden path of Late Greek thinking meontology and meontological difference in Damascius' De Principhs // Revue Roumaine de Philosophie. 2017. Vol. 61. Issue 1. Pp. 145-156.

31. Pierantoni C. Being-in-relation and self-knowledge in St. Augustine and Plotinus // Teologia y vida. 2015. Vol. 56. Issue 4. Pp. 431-460.

32. Piergiacomi E. Naming the Principles in Democritus: An Epistemological Problem // Apeiron. A Journal for Ancient Philosophy and Science. 2017. Vol. 50. Issue 4. Pp. 435-448.

33. Rist J. M. Plotinus: the road to reality. Cambridge University Press, 1967. 280 p.

34. Stamatellos G. Plotinus' concept of matter in Giordano Bruno's De la causa, principio et uno // British journal for the history of philosophy. 2018. Vol. 26. Issue 1. Pp. 11-24.

35. Tzamalikos P. Anaxagoras, Origen and Neoplatonism: the legacy of Anaxagoras to classical and late antiquity. Book Series: ArbeitenzurKirchengeschichte. Berlpn, 2016. Vol. 128. Pp. 421-487.

36. Vlad M. Stepping into the Void: Proclus and Damascius on Approaching the First Principle // The International Journal of the Platonic Tradition. 2017. Vol. 11. Issue 1. Pp. 44-68. 


\section{References}

1. Ado P. Negative theology. Ado P. Duhovnye uprazhneniya i antichnaya filosofiya. Moscow, St. Petersburg, Publishing house "Steppe Wind"; Publishing House "Kolo", 2005. 448 p. (In Russ.)

2. Bogomolov A.V. Dialectic solution of the problem of non-existence in the history of ancient Greek philosophy (pre-Socratic and classical stage): dissertation of the candidate of philosophical sciences: : 09.00.03. Nizhny Novgorod, 2014. 161 p. (In Russ.)

3. Bogomolov A.V. The separation of the categories of "nothing" and "non-existence" in the philosophy of Democritus. To justify the need for non-esseology. Credo new, 2012, no. 1, pp. 12-25. (In Russ.)

4. Vizgin V.YA. Interconnection of ontology and physics in the atomism of Democritus (by the example of the analysis of the concept of emptiness). Filosofiya prirody $v$ antichnosti $i v$ srednie veka. Moscow, 2000. Pp. 78-90. (In Russ.)

5. Vishnyakov V.P. Apophatic method in "Feast": between apheresis and apophase. Platonovskie issledovaniya, 2016, no. 2, pp. 164-186. (In Russ.)

6. Vorob'ev D.V. The role of nothing in the reality of mental constructions: the dissertation of the doctor of philosophical sciences: 09.00.01. Nizhny Novgorod, 2010. 359 p. (In Russ.)

7. Damaskij Diadoh. About the first principles: Aporia, relating to the first principles, and their resolution: A commentary on Plato's Parmenides. St. Petersburg, Publishing House of the Russian Christian Humanitarian Institute, 2000. 1071 p. (In Russ.)

8. Drobyshev V.N. Apophatic rationality and its transformation in modern Western philosophy: the dissertation of the doctor of philosophical sciences: 09.00.03. St. Petersburg, 2016. 338 p. (In Russ.)

9. Kayumov A.T., Krasil'nikov V.A. The essential characteristics of the differences in the consideration of the concept of "non-existence" on the example of the teachings of ancient Indian and ancient Greek philosophy. V mire nauchnyh otkrytij, 2015, no. 11(71), pp. 377-387. (In Russ.)

10. Losev A.F. The history of ancient aesthetics. Late Hellenism. Kharkiv, Folio Publ.; Moscow, Publishing House AST, 2000. 960 p. (In Russ.)

11. Lur'e S.YA. Democritus. Texts. Transfer. Research. Leningrad, Moscow, Science Publ., 1970. 666 p. (In Russ.)

12. Nothing / ed. D. Webb; per. from English A. Kapanadze. Moscow, Laboratory of Knowledge, 2016. 237 p. (In Russ.)

13. Opletaeva O.N. The origins and meaning of the apophatic tradition. Philosophy and Theology. Vestnik adygejskogo gosudarstvennogo universiteta. Seriya 1: Regionovedenie: filosofiya, istoriya, sociologiya, yurisprudenciya, politologiya, kul'turologiya, 2010, no. 4, pp. 30-36. (In Russ.)

14. Plotinus. Writings Plotinus in Russian translations. Moscow, St. Petersburg, Aletheia Publ. with the participation of the Greek-Latin cabinet Yu.A. Sichalina, 1995. 672 p. (In Russ.)

15. Rist Dzh.M. Plotinus: the path to reality / Per. from English E.V. Afonasina, I.V. Berestova. St. Petersburg, Publishing house of Oleg Abyshko, 2005. 320 p. (In Russ.)

16. Sobol'nikova E. N. "Conclusions about the impossible": to the problem of interpretation of mystical experience in the philosophy of Damascius Diadoh. Available at: http://www.plato.spbu.ru/CONFERENCES/2018/ther110.html (accessed: 20.04.2019). (In Russ.)

17. SHpeka K.A. To the problem of the content of the concept of non-existence. Filosofiya $i$ nauka, 2016, vol. 15, pp. 337-344. (In Russ.) 
18. Armstrong A.H. Plotinus Vol. VII, Ennead VI.6-9. Loeb Classical Library, 1988. 345 p.

19. Calvo J.M.Z. El primer principio, 'potencia de todas las cosas', en Plotino. Éndoxa: Series Filosóficas, 2016, issue 38, pp. 131-144.

20. Cohoe C.M. Why the One Cannot Have Parts: Plotinus on Divine Simplicity, Ontological Independence, and Perfect Being Theology. Philosophical quarterly, 2017, vol. 67(269), pp. 751-771.

21. Dillon J., Gershon L. Neoplatonic philosophy: introductory readings. Indianapolis: Hackett Publishing Co, 2004. 373 p.

22. Dodds E.R. The Parmenides of Plato and the Origin of the Neoplatonic 'One'. The Classical Quarterly, 1928, vol. 22, no. 3, pp. 129-142.

23. Dos Santos E. E. Leucipo, Demócrito e Kant: uma Reflexão sobre a Equivalência entre Ser e Não-Ser. TRANS-FORM-ACAO. 2015, vol. 38, issue 2, pp. 71-94.

24. Gerson L.P. The 'Neoplatonic' Interpretation of Plato's Parmenides. International journal of the platonic tradition, 2016, vol. 10, issue 1, pp. 65-94.

25. Gomes G.L. Elements in the atomism theory, according to Aristotle. Hypnos, 2018, issue 41, pp. 146-165.

26. Hadot P. Apophatisme et théologie negative. Exercices spirituels et philosophie antique. Paris. Études augustiniennes, 1987, pp. 185-193.

27. Hoffmann P. Les âges de l'Humanité et la critique du christianisme selon Damascius. La Revue de l'histoire des religions, vol. 234, issue. 4, pp. 737-775.

28. Lavaud L. The Primary Substance in Plotinus' Metaphysics: A Little-Known Concept. Phronesis, 2014, vol. 59, pp. 369-384.

29. Lee S. The Dynamic Association of Being and Non-Being: Heidegger's Thoughts on Plato's Sophist Beyond Platonism. Human studies, 2016, vol. 39, issue 3, pp. 385-403.

30. Moraru C.-F. The Forbidden path of Late Greek thinking meontology and meontological difference in Damascius' De Principhs. Revue Roumaine de Philosophie, 2017, vol. 61, issue 1, pp. 145-156.

31. Pierantoni C. Being-in-relation and self-knowledge in St. Augustine and Plotinus. Teologia y vida, 2015, vol. 56, issue 4, pp. 431-460.

32. Piergiacomi E. Naming the Principles in Democritus: An Epistemological Problem. Apeiron. A Journal for Ancient Philosophy and Science, 2017, vol. 50, issue 4, pp. 435-448.

33. Rist J. M. Plotinus: the road to reality. Cambridge University Press, 1967. 280 p.

34. Stamatellos G. Plotinus' concept of matter in Giordano Bruno's De la causa, principio et uno. British journal for the history of philosophy, 2018, vol. 26, issue 1, pp. 11-24.

35. Tzamalikos P. Anaxagoras, Origen and Neoplatonism: the legacy of Anaxagoras to classical and late antiquity. Book Series: Arbeiten zur Kirchengeschichte. Berlin, 2016.Vol. 128. Pp. 421-487.

36. Vlad M. Stepping into the Void: Proclus and Damascius on Approaching the First Principle. The International Journal of the Platonic Tradition, 2017, vol. 11, issue 1, pp. 44-68.

(C) Богомолов А.В., 2019

\section{Информация об авторе}

Богомолов Алексей Владимирович - кандидат философских наук, доцент кафедры философии и общественных наук, Нижегородский государственный педагогический университет имени Козьмы Минина (Мининский университет), Нижний Новгород, 


\section{History of philosophy}

Российская Федерация, ORCID ID: https://orcid.org/0000-0003-0286-7866, ResearcherID: S9623-2018, e-mail: ensestens@mail.ru

\section{Information about author}

Bogomolov Aleksey Vladimirovich - PhD, Associate Professor, Department of Philosophy and Social Sciences, Minin Nizhny Novgorod State Pedagogical University (Minin University), Nizhny Novgorod, Russian Federation, ORCID ID: https://orcid.org/0000-0003-0286-7866, ResearcherID: S-9623-2018, e-mail: ensestens@mail.ru

Поступила в редакцию: 24.03.2019

Принята к публикации: 30.04.2019

Опубликована: 05.06.2019 